\title{
Public stigma associated with mental illnesses in Pakistani university students: A cross sectional survey
}

Background: The objectives of the study were to explore the knowledge and attitudes of Pakistani university students toward mental illnesses. People with mental illnesses are challenged not only by their symptoms but also by the prejudices associated with their illness. Acknowledging the stigma of mental illness should be the first essential step toward devising an appropriate treatment plan. Methods: A cross-sectional survey was conducted at the University of Punjab, Lahore, CMH Lahore Medical and Dental College, Lahore, and University of Sargodha, Sub-campus Lahore, from February to May, 2014. The self-administered questionnaire consisted of three sections: demographics, general knowledge of psychiatric illnesses, and Community Attitudes towards Mental Illnesses (CAMI) Scale. The questionnaire was distributed to 650 participants enrolled in different disciplines (Social Sciences, Medicine and Formal Sciences). Results: Response rate was $81 \%$ (527/650 respondents). Mean age was 20.98 years. Most of the students $(331,62.8 \%)$ had an urban background and studied Social Sciences (238, 45.2\%). 418 (79.3\%) considered religion very important and most respondents considered psychiatrists (334, 63.4\%) and spiritual leaders $(72,13.7 \%)$ to be best able to treat mental illnesses. 169 (32.1\%) considered black magic to be a cause of mental illness. Only 215 (41\%) had ever read an article on mental illnesses. Multiple regression analysis revealed study discipline, exposure, perceived causes of mental illnesses and superstitions to be significantly associated with attitudes towards mental illnesses $(p<.05)$. Conclusion: Although low awareness and exposure were found in this sample of Pakistani university students, their attitude towards mental illnesses was generally positive. Most respondents gave supernatural explanations for mental illnesses but only a few believed that spiritual leaders can play a role in treatment. 
2 Ahmed Waqas ${ }^{1}$, Muhammad Zubair², Hamzah Ghulam², Muhammad Wajih Ullah²,

3 Muhammad Zubair Tariq ${ }^{2}$

$4 \quad{ }^{1}$ CMH Lahore Medical College and Institute of Dentistry, Shami Road, Lahore Cantt,

5 Pakistan

$6 \quad{ }^{2} \mathrm{FMH}$ College of Medicine and Dentistry, Lahore

7 Lead \& corresponding Author:

8 Ahmed Waqas

9 MBBS student (4th year)

10 Affiliated institute: CMH Lahore Medical College and Institute of Dentistry, Shami

11 Road, Lahore Cantt, Pakistan

12 Email Address: ahmedwaqas1990@hotmail.com

13 Phone number: +92-0343-4936117

14 Address: House \# 733, Street\# 5, Overseas-A, Bahria Town, Lahore

15 Funding support: None

16 Type of article: Original Article

17 Conflict of interest: None

18 Sponsorship: None

19 Disclosure: None

20 MeSH terms: Social stigma, Attitude, Social psychology, Mental illness

21 Original Article Word Count: 2723 words

22 Abstract Word Count: 279 words 


\section{Introduction}

24 In recent years much has been published about the stigma attached to mental

25 illnesses. However, most work to date has focused on western populations, and

26 there is a dearth of research literature on stigma in the developing world. People

27 with mental illness are one of the most stigmatized strata of our society. According

28 to Elliot and colleagues, public stigma associated with mental illnesses renders the

29 mentally ill socially illegitimate. They are perceived as incapable of normal

30 interaction, dangerous and unpredictable, and these perceptions lead to their

31 exclusion from the community (Elliott GC, Ziegler HL, \& Altman BM, 1982).

32 Therefore, they are challenged not only by their illness but also by the stigma and

33 stereotypes associated with them by the community.

34 In Pakistan, it is estimated that neuropsychiatric disorders account for $11.9 \%$

35 of the overall burden of disease (WHO, 2008). In developing countries, less than

$3635 \%$ of psychiatric patients receive care (WHO, 2001). Despite the availability of

37 psychiatric care (although meager), individuals often do not seek basic treatment

38 due to their fear of public stigma and shame. Therefore, psychiatrists who treat

39 people with mental illnesses have been encouraged to address the social context,

40 nature of adverse experiences, self-image and attitudes of the community.

41 Acknowledging negative attitudes towards mental illness should be the first step in

42 devising appropriate mental health policies and treatment plans (Byrne, 2000).

43 Failure to recognize public stigma and its effects can lead to isolation of people with

44 mental illness from the community (Goffman, 2009). Furthermore, people with

45 mental illness who justify and accept prejudice experience self-stigma, which can

46 lead to stress and compromise their capability for independent living (Corrigan,

47 Patrick \& Penn, 1999). Their increased stress may also cause psychological problems 
48 such as depression(Link et al., 1997), anxiety (Farina, 1981) and low self-esteem

49 (Link, 1987).

50 Pakistan is a culturally and ethnically diverse country that is home to a

51 number of religious branches of Islam whose practitioners can nurture very complex

52 belief systems. Beliefs in black magic, the evil eye and possession by Jinni (demons)

53 are prevalent in this society (pers. com. Gadit \& Callanan, 2006). Spiritual leaders

54 are revered and attract huge numbers of followers and devotees to their shrines.

55 The tendency to turn to spiritual resources has emerged as an effective coping

56 mechanism for various issues in this part of the world (Voll, 1992). Apart from

57 spiritual leaders, a huge number of shamans with no formal qualifications have also

58 emerged. This belief system of Pakistani society has implications for the knowledge

59 of and stereotypes attached to mental illnesses. As a result, people in this part of

60 the world, stricken by low literacy rates, poor socioeconomic conditions and

61 prevalent stigma, are hugely dependent on shamans for the treatment of mental

62 illnesses. Among the widely accepted causes of mental illnesses are possession by

63 demons and magical spells cast by enemies, and among the accepted treatments

64 are talismans, amulets and incantations (Gadit \& Reed, 2004).

65 The paucity of knowledge about public stigma, stereotypes and superstitions

66 prevailing in Pakistani society warranted this study, which was designed with three

67 aims: 1) to assess the prevalence of public stigma attached to mental illnesses in a

68 sample of university students in Pakistan, 2) to determine the reasons for these

69 stigmata, and 3) to determine the prevalence of supernatural beliefs and their effect

70 on stigmata attached to mental illnesses.

\section{Methods}

72 This cross-sectional survey was conducted in February, 2014 at the University of

73 Punjab, Lahore, CMH Lahore Medical and Dental College, Lahore and the University 
74 of Sargodha, Sub-campus Lahore. It was approved by the Ethics Review Committee

75 of CMH Lahore Medical College and Institute of Dentistry. An anonymous, self-

76 administered questionnaire was distributed (convenience sampling) to 650 students

77 enrolled in degree programs in various disciplines (Social Sciences, Medicine and

78 Formal Sciences) who were willing to participate in the survey. Written informed

79 consent was provided by each participant. They were informed about the objectives

80 of the survey and ensured anonymity and that only group-level (not individual)

81 findings would be reported.

82 The survey questionnaire consisted of three sections: demographic

83 information, a section assessing their knowledge of mental illnesses, and the

84 Community Attitudes toward the Mentally III (CAMI) Scale developed by Taylor and

85 Dear (1981). The first section recorded participants' demographic information. The

86 second section assessed whether they had any prior knowledge of and exposure to

87 mental illnesses. Three questions were asked: 1) Who can best cure mental

88 illnesses? A) General physician, B) Psychiatrist, C) Spiritual leader D) Other. 2) Have

89 you ever talked with a person with a mental illness, read books or articles about

90 mental illness, or cared for or had any relatives with mental illness? 3) What do you

91 think are the causes of mental illness? The participants indicated possible causes

92 from a table listing various causes of mental illnesses and superstitions. Multiple

93 responses were allowed.

94 The CAMI scale measures stigma and attitudes of the community towards

95 mental illnesses. It defines mental illness as referring to people needing treatment

96 for mental disorders but who are capable of independent living outside a hospital

97 (Taylor \& Dear, 1981). This scale consists of 40 statements with a Likert scale type of

98 response. The four subscales assess four types of attitudes towards mental illness.

99 "Authoritarianism" reflects oppressive attitudes towards the mentally ill,

100 "Benevolence" reflects a sympathetic attitude, "Social restrictiveness" considers the 
101 mentally ill as a threat to the society, and "Community mental health ideology

102 (CMHI)" supports the idea of community-oriented care for the mentally ill (Taylor \&

103 Dear, 1981). Each subscale comprises 10 items with 5 positively scored and 5

104 negatively scored items. Scores are reversed on negatively scored items and then

105 the total score for each subscale is calculated. The maximum score for each

106 subscale is 50.

107 The data was analyzed with SPSS v. 20 software. The chi-squared test and

108 Cramer's $V$ was used to find associations between demographic variables, prevalent

109 superstitions, study discipline, exposure and whether or not respondents believed

110 that shamans could play a therapeutic role in treating mental illness. Multiple

111 regression analysis (backward method) was used to identify associations between

112 demographic variables, exposure, knowledge of the true causes of mental illness,

113 prevalent superstitions and scores on each of the CAMI subscales.

114 For regression analysis, categorical variables with more than two categories,

115 such as background, importance of religion and study discipline, were coded as

116 dummy variables with 0 and 1 as coding values. A histogram was plotted to

117 visualize the distribution of the data as normal or non-normal, Probability-probability

118 (P-P) plots, the Durbin-Watson diagnostic test and colinearity diagnostics were run

119 to ensure that the assumptions of regression analysis were not violated. The level of

120 significance was set at $p<.05$.

\section{Results}

\section{Demographics}

123 The response rate was $81.1 \%$ (527 respondents out of 650 students who received

124 the questionnaire). Mean age of the respondents was 20.98 years (2.66), 312

125 (59.2\%) were females and 215 (40.8\%) males. Most students were enrolled in a 
126 Social Sciences degree program (238, 45.2\%), followed by Medicine (202, 38.3\%)

127 and Formal Sciences (87, 16.5\%). 331 (62.8\%) of the students came from an urban

128 background, 124 (23.5\%) from a rural background and 72 (13.7\%) from a semi-

129 urban background. 418 (79.3\%) considered religion very important, 102 (19.4\%)

130 considered it important and only 7 (1.3\%) felt religion was unimportant.

\section{Exposure to mental illnesses}

$132334(63.38 \%)$ participants believed that psychiatrists are best able to cure mental

133 illness, followed by general physicians $(79,14.99 \%)$, shamans or spiritual leaders

$134(72,13.66 \%)$ and others (42, 7.97\%). 215 (40.8\%) participants had ever read an

135 article or book on mental illness. Only $273(51.8 \%)$ had ever talked to a person with

136 mental illness, and 237 (45.0\%) had ever cared for a person with mental illness. 276

137 (52.4\%) had a relative with a mental illness. Chi-squared tests revealed a significant

138 association between having cared for the mentally ill (chi-squared $=4.56$ ) and the

139 study discipline (chi-squared $=6.27$ ) and punishment from God (chi-squared $=3.5$ )

140 as a cause of mental illness, and whether or not shamans or spiritual leaders were

141 believed to be best able to cure mental illnesses (all $p<.05$ ). According to these

142 results, respondents who had cared for someone with a mental illness, were enrolled

143 in the non-medical study discipline and considered punishment from God as a cause

144 of mental illness had a higher tendency to report that spiritual leaders were best

145 able to cure mental illnesses. No association was found between other superstitious

146 beliefs and whether spiritual leaders were best able to cure mental illnesses ( $p>$.

147 05).

148 Prevalent superstitions and knowledge of true psychopathologies

$149118(22.4 \%)$ students believed in the evil eye, 169 in black magic (32.1\%), 135

$150(25.6 \%)$ in punishment from God and $134(25.4 \%)$ in demonic possession as a cause 


\section{PeerJ Reviewing Manuscript}

151 of mental illness. The frequency distribution of true psychopathologies as reported

152 by participants was as follows: drug abuse, 278 (52.8\%); psychosocial trauma, 267

153 (50.7\%); alcohol abuse, 180 (34.2\%); work-related stress, 301 (57.1\%); genetic

154 predisposition, 211 (40\%); physical abuse, 241 (45.7\%); poverty, 184 (34.9\%);

155 study-related stress, 236 (44.8\%); and divorce, 260 (49.3\%). Chi-squared tests

156 revealed significant associations between study disciplines (Medicine vs. Non-

157 medicine), superstitions and true psychopathologies. Only those variables that

158 yielded significant associations are shown in Table 1 . This table reflects the finding

159 that medical students were more likely to report psychosocial trauma, work-related

160 stress, genetic predisposition towards mental illnesses, physical abuse, study-related

161 stress and divorce as causes of mental illness. In contrast, non-medical students

162 were more likely to report the evil eye, punishment from God and possession by Jinni

163 (demons) as possible causes of mental illnesses.

164 Background and belief in superstitions

165 The background of participants also showed a statistically significant association

166 with superstitions (Table 2). Participants with a rural background were more likely to

167 identify superstitions as the cause of mental illness.

168 CAMI subscale scores and determinants

169 The median scores of participants on CAMI subscales were Authoritarian 29,

170 Benevolence 36, Social restrictiveness 28 and Community mental health attitude

171 (CMHI) 32.5. Multiple regression analysis (backward method) was run for the

172 subscale scores with demographic variables, exposure, superstitions and true

173 psychopathologies as variables predictive of the variance in scores on the different

174 subscales. Only the final models are reported in Tables 3, 4, 5 and 6. 


\section{PeerJ Reviewing Manuscript}

\section{Discussion}

176 The study sample consisted of undergraduate students enrolled in three universities

177 in Lahore and therefore reflects the attitudes of literate strata of Pakistani society.

178 Overall, the participants had favorable attitudes towards people with mental illness,

179 as reflected by their scores on the CAMI subscales. They scored lower on the

180 Authoritarian and Social restrictiveness subscales and higher on the Benevolence

181 and $\mathrm{CMHI}$ subscales. Comparatively, medical students had more positive attitudes

182 towards people with mental illness than students enrolled in nonmedical study

183 disciplines. Students who had read books or articles, cared for or talked with people

184 with mental illness were less authoritative and less socially restrictive, more benevolent, and had a more favorable community attitude. Behavioral sciences are an integral part of the undergraduate medical curriculum in Pakistani medical

187 schools. Accordingly, most medical students in this survey already had a better knowledge of mental illnesses than students in other disciplines. Moreover, most medical students were already involved in clinical training, so their exposure to people with mental illnesses was greater. This may have led medical students to adopt more lenient attitudes towards people with mental illnesses compared to 192 students in nonmedical disciplines.

193 Overall, participants had a poor knowledge of the biopsychosocial causes of 194 mental illness. This finding is consistent with other studies carried out in England 195 (Evans-Lacko, Henderson \& Thornicroft, 2013) from 2009 to 2012 and in Egypt 196 (Dessoki \& Hifnawy, 2009). Respondents in our study expressed better knowledge of 197 the true causes of mental illnesses and hence more positive attitudes than those reported by Gureje et al. (Gureje et al., 2005), probably because the present study

199 included university students only rather than the general public. Knowledge of the 200 general public in Pakistan regarding mental illnesses might be similar to that found 201 by Gureje and colleagues. 
203 illnesses and stigmatizing attitudes. In a similar study conducted by Gureje et al., 204 these causes fell into two domains: biopsychosocial and religio-magical. The former 205 group had more tolerant attitudes towards people with mental illnesses (Gureje et 206 al., 2006). The present analysis, however, yielded slightly different results. It may be 207 informative to further subclassify these domains in order to explore in more detail 208 the relationship between knowledge of the causes and attitudes towards mental 209 illness. In contrast to Gureje et al., participants in the present study who reported 210 substance abuse, alcoholism and poverty as causes of mental illness were generally 211 more authoritative and socially restrictive, less benevolent, and had less favorable 212 community attitudes. Compared to other biopsychosocial causes, substance abuse 213 and alcoholism elicited negative attitudes because of beliefs that alcoholics and 214 drug abusers are dangerous, unpredictable, capable of helping themselves and more 215 responsible for their condition (Crisp et al., 2000). These attitudes consequently lead 216 to greater public stigma, negative attitudes and social rejection (Schomerus et al., 217 2011).

218 Greater religiosity correlated directly with more authoritative attitudes, 219 reflecting oppressive attitudes towards people with mental illnesses. A similar study 220 in Benin reported more authoritative attitudes among members of the Muslim clergy 221 (Igbinomwanhia, James \& Omoaregba, 2013), in consonance with the potential 222 influence of religious beliefs on the perceived stigma of mental illness. The belief 223 that mental illness might indicate spiritual failure potentiates stigma and may 224 discourage individuals from seeking psychiatric care (Trice, Pamela \& Bjorck, 2006). 225 Superstitious beliefs such as black magic, the evil eye, punishment from God 226 and demonic possession as causes of mental illnesses were highly prevalent among 227 the participants in the present study. Generally, these beliefs tended to be 228 associated with less favorable attitudes among university students towards persons 
229 with mental illness. Medical students were less likely to report supernatural causes

230 of mental illnesses, and participants from a rural background tended to identify

231 supernatural causes of mental illnesses more frequently than those with an urban or

232 semi-urban background. The former also had less benevolent attitudes towards

233 people with mental illness. In a recent study, rural residents were much more likely

234 to believe in superstitions such as black magic and the healing powers of talismans

235 and Sufi shrines (Farooq, 2012). Three reasons were reported for believing in

236 superstitions: experience, tradition and religion. A much smaller percentage of

237 students in the present sample believed that shamans could play a therapeutic role

238 in mental illness. This reflects a general lack of trust among more literate persons in

239 the therapeutic abilities of shamans.

240 The stigma associated with mental illness is highly prevalent in Pakistani

241 society. To reduce the stigma, barriers to care and the shame associated with

242 seeking psychiatric help, WHO recommends launching mass awareness programs in

243 all countries to raise the public's knowledge and awareness of the frequency,

244 treatment and recovery process for mental disorders (WHO, 2001). These psycho-

245 educational campaigns should be designed according to the needs of specific

246 groups, addressing their attitudes, fear and concerns pertaining to mental illnesses.

247 These educational interventions and appropriate exposure can decrease the stigma

248 associated with mental illnesses not only among undergraduate medical students

249 (Papish et al, 2013) but also among students of other disciplines and grades (Pinfold 250 et al., 2003).

\section{Limitations \& Recommendations}

252 The results of this study cannot be generalized as the population sample was not

253 obtained randomly. The use of a self-administered questionnaire may have led to

254 information bias. The cross-sectional design of this study limits inferences about 
255 causality between exposure, perceived causes and attitudes towards mental illness.

256 Religiosity was measured with a single question: How important is religion in your

257 life? For future studies the use of a reliable scale is advisable. Although an item

258 regarding socioeconomic status was included in the questionnaire, 75 respondents

259 left it blank it. Therefore, this variable was excluded from the analysis.

260 Conclusion

261 Although overall awareness of and exposure to mental illness were low in this

262 sample of university students, their attitudes towards mental illnesses were

263 generally positive. Most students expressed a belief in supernatural explanations for

264 mental illnesses, whereas only a few believed that spiritual leaders can play a role in

265 their treatment.

\section{Acknowledgments}

267 The authors I thank Aroosa Allah Yar and Arooj Allah Yar, students at Hailey College 268 of Commerce, Punjab University, Lahore, Pakistan, and Abeer Asfaq, Azfar Hameed, 269 Hamza Bukhari, Zahra Malik and Nur Ghani, students at CMH Lahore Medical and 270 Dental College, for helping with data collection for this project. I also thank K.

271 Shashok (AuthorAID in the Eastern Mediterranean) for improving the use of English 272 in the manuscript. 
273

274

275

276

277

278

279

280

281

282

283

284

285

286

287

288

289

290

291

292

293

294

295

296

297

298

299

300

301

302

303

304

\section{References}

Farina A. 2001. Are women nicer people than men? Sex and the stigma of the mental disorders. Clinical Psychology Review l:223-243.

Byrne P. 2000. Stigma of mental illness and ways of diminishing it. Advances in Psychiatric Treatment 6:65-72.

Corrigan, Patrick W, Penn DL. 1999. Lessons from social psychology on discrediting psychiatric stigma. American Psychologist 54:765-776.

Crisp AH, Gelder GM, Rix S, Meltzer HI, Olwen JR. 2000. Stigmatisation of people with mental illnesses. The British Journal of Psychiatry 177:4-7.

Dessoki HH, \& Hifnawy TMS. 2009. Beliefs about mental illness among university students in Egypt. Europe's Journal of Psychology 5:1-19.

Elliott GC, Ziegler HL, Altman BM, Scott DR. 1982. Understanding stigma: dimensions of deviance and coping. Deviant Behaviour 3:275-300.

Evans-Lacko S, Henderson C, Thornicroft G. 2013. Public knowledge, attitudes and behaviour regarding people with mental illness in England 2009-2012. The British journal of psychiatry. Supplement 55:s51-7.

Farooq A. 2012. Prevalence of Superstitions and other Supernaturals in Rural Punjab: A Sociological Perspective. South Asian Studies 27:335-344.

Gadit AAM, Callanan TS. 2006. Opinion and Debate Jinni Possession : A clinical enigma in mental health Mind Possession : One View. JPMA 56:476-478.

Gadit AAM, Reed V. 2004. Culture and mental health: Pakistan's perspective. Hamdard Foundation, Karachi 1st Edition:38-44.

Goffman E. 2009. Stigma: Notes on the management of spoiled identity. Simon and Schuster. Penguin Books, London.

Gureje O, Lasebikan VO, Ephraim-Oluwanuga O, Olley BO, Kola L. 2005. Community study of knowledge of and attitude to mental illness in Nigeria. The British Journal of Psychiatry 186:436-41.

Gureje O, Olley BO, Olusola E-O, Kola L. 2006. Do beliefs about causation influence attitudes to mental illness? World Psychiatry 5:104-7.

Igbinomwanhia NG, James BO, Omoaregba JO. 2013. The attitudes of clergy in Benin City, Nigeria towards persons with mental illness. African Journal of Psychiatry 16:196-200. 
305

306

307

308

309

310

311

312

313

314

315

316

317

318

319

320

321

322

323

324

325

326

327

328

329

330

331

332

Link BG. 1987. Understanding labeling effects in the area of mental disorders: An assessment of the effects of expectations of rejection. American Sociological Review 52:96-112.

Link BG, Struening EL. , Rahav M, Phelan JC. and Nuttbrock L. 1997. On stigma and its consequences: evidence from a longitudinal study of men with dual diagnoses of mental illness and substance abuse. Journal of Health and Social Behavior 38:177-190.

Papish A, Kassam A, ModgilL G, Vaz G, Zanussi L, Patten S. 2013. Reducing the stigma of mental illness in undergraduate medical education: a randomized controlled trial. BMC medical education 13:141.

Pinfold V, Toulmin H, Thornicroft G, Huxley P, Farmer P, Graham T. 2003. Reducing psychiatric stigma and discrimination : evaluation of educational interventions in UK secondary schools Reducing psychiatric stigma and discrimination: evaluation of educational interventions in UK secondary schools. The British Journal of Psychiatry 182:342-346.

Schomerus G, Lucht M, Holzinger A, Matschinger H, Carta MG, Angermeyer MC. 2011. The stigma of alcohol dependence compared with other mental disorders: a review of population studies. Alcohol and Alcoholism (Oxford, Oxfordshire) 46:105-12.

Taylor SM, and Dear MJ. 1981. Scaling community attitudes toward the mentally ill. Schizophrenia Bulletin 7:225-240.

Trice, Pamela D., and Bjorck JP. 2006. Pentecostal perspectives on causes and cures of depression. Professional Psychology: Research and Practice 37:283.

Voll JO. 1992. Conservative and Traditional Brotherhoods. Annals of the American Academy of Political and Social Sciences 524:66-78.

WHO. 2001. World Health Report, Geneva, Switzerland.

WHO. 2008. Mental Health Atlas, Geneva, Switzerland.

WHO. 2001. The way forward: WHO recommendations. 
Table $\mathbf{1}$ (on next page)

Association between study discipline and belief in causes of mental illness

Association (chi-squared test) between study discipline (medicine vs. nonmedicine) and beliefs in causes of mental illness 
Table 1: Association (chi-squared test) between study discipline (medicine vs. non-medicine) and beliefs in causes of mental illness

\begin{tabular}{|c|c|c|c|}
\hline Causes of mental illness & $\begin{array}{l}\text { Chi- } \\
\text { squared } \\
\text { value }\end{array}$ & $\begin{array}{l}\text { Degrees of } \\
\text { freedom (df) }\end{array}$ & $\begin{array}{l}\text { Cramer's } \\
\mathrm{V}\end{array}$ \\
\hline Trauma & $165.19^{* * *}$ & 1 & $.560 * * *$ \\
\hline Work stress & $21.57^{* * *}$ & 1 & $.202 * * *$ \\
\hline Genetic predisposition & $34.54 * * *$ & 1 & $.256^{* * *}$ \\
\hline Physical abuse & $59.20 * * *$ & 1 & $.335^{* * *}$ \\
\hline Study-related stress & $20.28^{* * *}$ & 1 & $.196 * * *$ \\
\hline Divorce & $27.92^{* * *}$ & 1 & $.198^{* * *}$ \\
\hline Evil eye & $6.96^{*}$ & 1 & $.230 *$ \\
\hline Punishment from God & $18.14^{* * *}$ & 1 & $.186^{* * *}$ \\
\hline Demonic possession & $10.77^{* * *}$ & 1 & $.143^{* * *}$ \\
\hline
\end{tabular}

***p value $<.001, * \mathrm{p}$ value $<.05$ 
Table 2 (on next page)

Association between background and belief in superstitious causes of mental illnesses

Association (chi-squared test) between background (rural vs. other) and beliefs in superstitious causes of mental illness 
Table 2: Association (chi-squared test) between background (rural vs. other) and beliefs in superstitious causes of mental illness

\begin{tabular}{|l|l|l|l|}
\hline Variable & $\begin{array}{l}\text { Chi-squared } \\
\text { value }\end{array}$ & $\begin{array}{l}\text { Degrees of freedom } \\
(\mathrm{df})\end{array}$ & Cramer's V \\
\hline Punishment from God & $22.66^{* * *}$ & 1 & $.21^{* * *}$ \\
\hline Demonic possession & $10.1^{* *}$ & 1 & $.14^{* *}$ \\
\hline
\end{tabular}

${ }^{* * *} \mathrm{p}<.001,{ }^{* *} \mathrm{p}<.01$ 
Table 3(on next page)

Predictors of Authoritarian subscale

Table 3: Multiple regression analysis for the CAMI Authoritarian subscale 
Table 3: Multiple regression analysis for the CAMI Authoritarian subscale

\begin{tabular}{|l|l|l|l|}
\hline Predictor & $\mathrm{B}$ & $\begin{array}{l}\text { Standard error of } \\
\text { B }\end{array}$ & $\boldsymbol{\beta}$ \\
\hline Constant & 28.876 & .487 & \\
\hline Study discipline & -1.894 & .361 & $-.226^{* * *}$ \\
\hline Ever read & -1.204 & .341 & $-.145^{* * *}$ \\
\hline Drug abuse & .677 & .334 & $.083^{*}$ \\
\hline $\begin{array}{l}\text { Genetic } \\
\text { predisposition }\end{array}$ & -.698 & .352 & $-.084^{*}$ \\
\hline $\begin{array}{l}\text { Punishment from } \\
\text { God }\end{array}$ & 1.333 & .383 & $.143^{* * *}$ \\
\hline Religion & 1.069 & & \\
\hline Adjusted $\mathrm{R}^{2}=.159 * \mathrm{p}<.05, * * \mathrm{p}<.01, * * * \mathrm{p}<.001$ & $.106^{*}$ \\
\hline
\end{tabular}

Adjusted $\mathrm{R}^{2}=.159,{ }^{*} \mathrm{p}<.05,{ }^{* *} \mathrm{p}<.01,{ }^{* * *} \mathrm{p}<.001$ 


\section{Table 4(on next page)}

Predictors of Benevolence subscale

Table 4: Multiple regression analysis for the CAMI Benevolence subscale 
Table 4: Multiple regression analysis for the CAMI Benevolence subscale

\begin{tabular}{|l|l|l|l|}
\hline Predictor & $\mathrm{B}$ & $\begin{array}{l}\text { Standard error of } \\
\end{array}$ & $\mathrm{B}$ \\
\hline Constant & 34.142 & .467 & \\
\hline Study discipline & 2.363 & .534 & \\
\hline Drug abuse & 1.039 & .452 & $.209^{* * *}$ \\
\hline Trauma & 2.248 & .525 & $.095^{*}$ \\
\hline Alcohol & -1.382 & .490 & $.205^{* * *}$ \\
\hline Work-related stress & 1.077 & .435 & $-.119^{* *}$ \\
\hline Physical abuse & .864 & .483 & $.097^{*}$ \\
\hline Evil eye & -1.896 & .509 & $.078^{*}$ \\
\hline Poverty & -1.429 & .461 & $-.144^{* * *}$ \\
\hline Background (rural & -1.256 & .515 & $-.124^{* *}$ \\
vs. other) & & & $-.097^{*}$ \\
\hline Adjusted $\mathrm{R}^{2} .251, * 0<.05, * * p<.01, * * * p<.001$ & \\
\hline
\end{tabular}

Adjusted $\mathrm{R}^{2}=.251,{ }^{*} \mathrm{p}<.05,{ }^{* *} \mathrm{p}<.01,{ }^{* * *} \mathrm{p}<.001$ 
Table 5 (on next page)

Predictors of social restrictiveness subscale

Table 5: Multiple regression analysis for the CAMI Social restrictiveness subscale " 
Table 5: Multiple regression analysis for the CAMI Social restrictiveness subscale

\begin{tabular}{|c|c|c|c|}
\hline Predictor & $B$ & $\begin{array}{l}\text { Standard error of } \\
\text { B }\end{array}$ & $\boldsymbol{\beta}$ \\
\hline Constant & 29.067 & .324 & \\
\hline Ever talked & -.757 & .335 & $-.097 *$ \\
\hline Ever cared & -.550 & .333 & $-.070 *$ \\
\hline Trauma & -1.651 & .357 & $-.211 * * *$ \\
\hline Genetic & -.622 & .362 & $-.078 *$ \\
\hline Evil eye & .743 & .408 & $.079 *$ \\
\hline Poverty & .866 & .350 & $.105^{*}$ \\
\hline $\begin{array}{l}\text { Punishment from } \\
\text { God }\end{array}$ & .871 & .388 & $.097 *$ \\
\hline
\end{tabular}

Adjusted $\mathrm{R}^{2}=.107,{ }^{*} \mathrm{p}<.05,{ }^{* *} \mathrm{p}<.01,{ }^{* * *} \mathrm{p}<.001$ 


\section{Table 6(on next page)}

Predictors of $\mathrm{CMHI}$ subscale

Table 6: Multiple regression analysis for the CAMI CMHI subscale 
1Table 6: Multiple regression analysis for the CAMI CMHI subscale

\begin{tabular}{|l|l|l|l|}
\hline Predictor & $\mathrm{B}$ & $\begin{array}{l}\text { Standard error of } \\
\text { B }\end{array}$ & $\boldsymbol{\beta}$ \\
\hline Constant & 30.733 & .536 & \\
\hline Study discipline & 1.657 & .446 & $.185^{* * *}$ \\
\hline Ever read & .795 & .362 & $.090^{*}$ \\
\hline Trauma & 1.821 & .425 & $.209^{* * *}$ \\
\hline Poverty & -.931 & .374 & $-.102^{*}$ \\
\hline Punishment by God & -1.044 & .418 & $-.105^{*}$ \\
\hline $\begin{array}{l}\text { Demonic } \\
\text { possession }\end{array}$ & -.909 & .414 & $-.091^{*}$ \\
\hline
\end{tabular}

3

4 